\title{
Electronic cigarettes: the solution or yet another phase of the tobacco epidemic?
}

\author{
Catherine O Egbe', Charles DH Parry',2 \\ and Bronwyn Myers ${ }^{1,3}$
}

\begin{abstract}
Tobacco use is the single largest preventable cause of death globally. For years, the tobacco industry sought to create a tobacco product that is less controversial than conventional cigarettes. Electronic cigarettes were created out of the supposed need to supply consumers of tobacco products with a less harmful tobacco product. The question remains, is it really less harmful for consumers of traditional cigarettes and other tobacco products to switch to electronic cigarettes? This article takes a closer look at the overall harm in relation to benefits of using electronic cigarettes for the individual and public health and the unintended negative consequences the introduction of electronic cigarette has had on overall public health. Given the evidence that the use of electronic cigarettes is a gateway to the use of other tobacco products especially among adolescents, we view electronic cigarettes as having the potential to cause a rebound of the tobacco use glut which the global public health community has been succeeding in reversing. We therefore support the World Health Organization's suggestion that electronic cigarettes should be regulated as other tobacco products since there is, as yet, no harmless tobacco product. In the same vein, we view the new Tobacco Products and Electronic Delivery Systems Bill seeking to regulate electronic cigarettes in South Africa as other tobacco products as a step in the right direction.
\end{abstract}

\section{Keywords}

Electronic cigarettes, nicotine, smoking, substance use, tobacco, vaping

\footnotetext{
'Alcohol, Tobacco and Other Drug Research Unit, South African Medical Research Council, South Africa 2Department of Psychiatry, Stellenbosch University, South Africa

${ }^{3}$ Department of Psychiatry and Mental Health, University of Cape Town, South Africa
}

\section{Corresponding author:}

Catherine O Egbe, Alcohol, Tobacco and Other Drug Research Unit, South African Medical Research Council, I Soutpansberg Road, Pretoria 000I, South Africa.

Email: catherine.egbe@mrc.ac.za 


\section{Introduction}

Cigarette smoking is the single largest preventable cause of death globally (Proctor, 2011). It is therefore logical that cigarette smokers seek products which could pose little or no risk to their health but feed their addiction to nicotine. Electronic cigarettes (e-cigarettes) have been promoted by manufacturers and some public health advocates as a less harmful tobacco product (Benowitz \& Goniewicz, 2013), as well as a smoking cessation aid (Shi et al., 2016). This explains why many smokers (and non-smokers) of traditional cigarettes have positive perceptions about e-cigarettes (Amrock, Zakhar, Zhou, \& Weitzman, 2015). However, the key question for public health is whether the introduction of e-cigarettes will contribute to reductions in cigarette smoking or if the product poses a new public health problem by becoming a pathway for recruiting new tobacco users and getting more people addicted to nicotine.

E-cigarette smoking is also called 'vaping' and has become a highly controversial tobacco product (Chang \& Barry, 2015) constantly attracting debate from both the pro- and anti-harm reduction camps of the public health community (Warner \& Mendez, 2018). An e-cigarette is an aerosol which contains nicotine (usually), glycerol, propylene glycol, flavourings, and other chemicals (Callahan-Lyon, 2014). Modern electronic cigarettes can be traced to the Chinese pharmacist, Hon Lik, in 2004 (Demick, 2009). Tobacco industry documents show that tobacco companies developed electronic nicotine delivery systems as far back as 1963 (Dutra, Grana, \& Glantz, 2017), and an earlier model of e-cigarette was patented in 1965 to Gilbert Herbert in the United States (US Department of Health and Human Services, 2016).

E-cigarettes were first conceived as a 'harmless' replacement for combustible cigarettes (US Department of Health and Human Services, 2016) to address the growing criticisms of tobacco use (Elias \& Ling, 2018), particularly because of the link between tobacco and various cancers, especially lung cancer (US Department of Health and Human Services, 1964). Yet the e-cigarette agenda is more complex than it appears. Tobacco manufacturers, many of whom also manufacture e-cigarettes, while fighting strong tobacco control legislations around the world (ABC News, 2018; Agence France-Presse (AFP), 2016; Campaign for Tobacco-Free Kids, 2018; McGhee, 2017), keep introducing novel tobacco products with exotic flavours which are more attractive to young people than traditional tobacco products (Farrelly et al., 2015). In fact, the aim of emerging tobacco products like e-cigarettes seems not to replace traditional cigarettes with less harmful products, but rather to divert the discussion around the negative health effects of tobacco products (Dutra et al., 2017). These novel products are expanding the market for tobacco manufacturers and allowing them to evade regulations around marketing and use of tobacco products in public spaces (Dutra et al., 2017).

In 2016, the US Surgeon General's report was dedicated to e-cigarette use among young people (US Department of Health and Human Services, 2016). The report highlighted the fact that e-cigarettes have become the most popular tobacco products among youth and young adults in the United States (US Department of Health and Human Services, 2016). This is not presently the case in South Africa due to the high price of e-cigarettes and associated delivery devices, but this could change if the products begin to be locally manufactured.

\section{Harmful effects of e-cigarettes}

Studies have found that e-cigarettes are generally regarded as a safer tobacco product by smokers and non-smokers alike (Abo-Elkheir \& Sobh, 2016; Amrock et al., 2015). However, it is also recognized that this product carries its own health risks due to fine and ultrafine particles released in the vapour (including non-nicotine containing liquids [e-liquids]) which become easier to be 
deposited in deeper parts of the respiratory system leading to increased risk of cardiovascular diseases (Fromme \& Schober, 2015; Lerner et al., 2015). E-cigarette users are exposed to as much nicotine as smokers of traditional cigarettes (Göney, Çok, Tamer, Burgaz, \& Şengezer, 2016; Goniewicz et al., 2017). Nicotine is known to be one of the hazardous components of traditional tobacco products and is highly addictive (Siqueira, 2017).

However, a lot is still unknown about the harmful effect of e-cigarette use (Rubinstein, Delucchi, Benowitz, \& Ramo, 2018). Many studies are underway to examine potential harms, and it is possible that these will yield additional evidence of e-cigarette-related health harms in the future. In the meantime, the public perception, promoted by the manufacturers and some public health advocates, that e-cigarettes are a less harmful tobacco product (Rubinstein et al., 2018) seems to have contributed to the acceptance and popularity of the product (Abo-Elkheir \& Sobh, 2016; Ambrose et al., 2014; Amrock et al., 2015; Barrington-Trimis et al., 2015). Even though the evidence of e-cigarette-related harms is still emerging, users of e-cigarettes must be made aware that there is no safe tobacco product. As mentioned earlier, e-cigarette vapour has been found to contain toxic chemicals and is not as safe as it is being promoted (Rubinstein et al., 2018). Also, the e-cigarette aerosol and e-liquid have been found to produce trace elements, like cadmium, lead, and nickel, which are known carcinogens (Gaur \& Agnihotri, 2018). Taking into consideration the doseresponse relationship between cigarette use and harm, frequency of using e-cigarette (which may be high given the perception that it is a less harmful tobacco product) will likely erode any potential gains of using a non-combustible tobacco product (Bhatnagar, 2016).

In what has been described as the best model of population-level estimation of harm and benefit, e-cigarette use was found to have an overall more harmful effect than a reduced-harm effect (Soneji, Sung, Primack, Pierce, \& Sargent, 2018). The Monte Carlo stochastic simulation model used in this study factored in the assumption of the relative harm of using e-cigarettes compared to traditional cigarettes (Soneji et al., 2018).

\section{E-cigarettes promoting smoking and reducing likelihood of quitting}

There is mounting evidence from several countries that e-cigarette use predicts initiating the use of traditional tobacco products among young people (East et al., 2018; Morgenstern, Nies, Goecke, \& Hanewinkel, 2018; Primack, Soneji, Stoolmiller, Fine, \& Sargent, 2015; Soneji et al., 2017; Wang et al., 2015; Zhong, Cao, Gong, Fei, \& Wang, 2016). Another worrisome move of the e-cigarette manufacturers is the production of child/youth-friendly flavours of e-liquids like strawberry, chocolate, cotton candy, bubble gum, and apple. Exotic flavours like fruits and candy (Pepper, Ribisl, $\&$ Brewer, 2016) are known to be more attractive to young people (Ford, MacKintosh, Bauld, Moodie, \& Hastings, 2016) and may perhaps explain why young people are so attracted to e-cigarettes (Barnett, Soule, Forrest, Porter, \& Tomar, 2015; Barrington-Trimis et al., 2016).

Studies have also shown that the use of e-cigarettes as a smoking cessation aid is not as effective as is being promoted (Shi et al., 2016). Instead, some studies have found that e-cigarette use reduces the likelihood of people quitting tobacco use (Al-Delaimy, Myers, Leas, Strong, \& Hofstetter, 2015; Rigotti et al., 2018).

\section{Regulating e-cigarettes}

The finding that e-cigarette use is a gateway to using traditional cigarettes among young people has resulted in calls for stricter regulation of the manufacturing, advertisement, and sale of e-cigarettes as advised by the WHO Framework Convention on Tobacco Control (WHO FCTC, 2016). The 
regulation of e-cigarettes has also experienced as much controversy as the product itself. Initially, e-cigarette manufacturers argued that the product was not a tobacco product and should not be regulated as such. The promotion of e-cigarettes as a non-tobacco product was, however, contradicted when the tobacco industry began promoting it as a reduced-harm tobacco product. The WHO FCTC recommends that e-cigarettes be prohibited or restrictions be placed on their manufacturing, importation, distribution, presentation, sale and use, and on associated products (WHO FCTC, 2016). Presently, 83 countries now regulate e-cigarettes as tobacco products (Global Tobacco Control, n.d.a), while 27 countries including 4 African countries (Gambia, Mauritius, Seychelles, and Uganda) have banned the sale of e-cigarettes (Egbe, 2018; Global Tobacco Control, n.d.-b).

\section{Towards preventing a rebound of tobacco use globally}

Tobacco use has been in existence since pre-historic times (Proctor, 2011), but cigarette smoking became more popular in the late 20th century with the commercial manufacturing of cigarettes, taxation, mass marketing, the invention of flue-curing and matches, among other factors (Proctor, 2011). Tobacco control has achieved much progress in reducing the global prevalence of tobacco use, especially with the introduction of the WHO Framework Convention on Tobacco Control in 2003 (World Health Organization (WHO), 2003). However, the success recorded in tobacco control may be eroded if manufacturers of e-cigarettes are allowed to continue promoting the product as a replacement for 'harmful' cigarettes with new names, or as a smoking cessation aid. This stance only serves to circumvent tobacco control laws (Auer, Concha-Lozano, Jacot-Sadowski, Cornuz, \& Berthet, 2017) and make e-cigarettes, and indeed traditional cigarettes, more attractive to the youth who have long been considered replacement smokers by the tobacco industry (Perry, 1999).

Apart from strong policies and regulatory controls, the only thing that may limit e-cigarette use could be affordability to people of low socio-economic status. However, there is the possibility of a price plunge, should a cheaper means of production be discovered or there is enough competition among e-cigarette manufacturers to cause a fall in the price. It will be a catastrophic twist for tobacco control if the price of e-cigarettes falls and the product becomes more affordable to young people, especially in low- and middle-income countries (LMIC). If e-cigarette prices drop, tobacco control advocates, and indeed all stakeholders in tobacco control may be dealing with a potential time bomb and an explosion of not only e-cigarette use but also the use of other tobacco products by young people. This will erode the gains of tobacco control of the past few years.

\section{South Africa and e-cigarettes}

Several electronic cigarette brands are sold in South Africa with little or no restrictions. South Africa is the only country where iQOS (I-Quit-Ordinary-Smoking) product is sold. iQOS is a variant of electronic cigarette produced by Philip Morris International (PMI; Gilbert, 2017) with a high-tech look and sophisticated marketing. PMI promotes iQOS as a 'smoke-free' tobacco product with a 'heat-not-burn' technology (Gilbert, 2017). Research, however, found that iQOS had $84 \%$ of the nicotine level of conventional cigarettes as well as other carcinogenic substances (Auer et al., 2017). The current tobacco control law in South Africa (Republic of South Africa, 2008) does not regulate any e-cigarettes and electronic nicotine or non-nicotine products. This makes consumers of e-cigarettes in South Africa vulnerable to misinformation about the risks and perceived benefits of using the product (Muposhi \& Dhurup, 2016). With the introduction of a new tobacco bill (National Department of Health, 2018) in South Africa, which would repeal and replace the old tobacco control law (Republic of South Africa, 2008), electronic cigarettes and their accessories will soon be regulated as tobacco products. This is a promising development that hopefully will curtail the spread and social acceptance of iQOS and other e-cigarette products in South Africa. 


\section{Conclusion}

E-cigarette products have evolved over the years (Benowitz \& Goniewicz, 2013). With the variation in engineering of the e-cigarette devices, type and flavour of the e-liquid, and the smokers' individual smoking patterns, there has been varied outcomes on the effect of e-cigarettes on the human body (DeVito \& Krishnan-Sarin, 2018). The variation in the e-cigarette accessories and liquids also makes it problematic to make generalized statements about the toxicity and effects of these products (Benowitz \& Goniewicz, 2013). More research needs to be conducted to unravel the health risks associated with each aspect of e-cigarettes to be at par with what is currently known about the harms of traditional cigarettes. In the meantime, e-cigarette advocates must apply caution in promoting the product as a reduced harm and smoking cessation aid. In relation to public health, it is safer to err on the side of caution than to risk the lives of millions of individuals.

\section{Funding}

The author(s) received no financial support for the research, authorship, and/or publication of this article.

\section{References}

ABC News. (2018). Australia wins landmark World Trade Organization ruling on tobacco plain packaging laws. Retrieved from http://www.abc.net.au/news/2018-06-29/australia-wins-landmark-wto-ruling-ontobacco-plain-packaging/9921972

Abo-Elkheir, O. I., \& Sobh, E. (2016). Knowledge about electronic cigarettes and its perception: A community survey, Egypt. Respiratory Research, 17, 58.

Agence France-Presse. (2016). Plain packaging laws survive international court as Philip Morris warned over 'abuse of rights'. Retrieved from http://www.abc.net.au/news/2016-05-17/philip-morris-loseslegal-battle-against-plain-packaging-laws/7420356

Al-Delaimy, W. K., Myers, M. G., Leas, E. C., Strong, D. R., \& Hofstetter, C. R. (2015). E-cigarette use in the past and quitting behavior in the future: A population-based study. American Journal of Public Health, 105, 1213-1219.

Ambrose, B. K., Rostron, B. L., Johnson, S. E., Portnoy, D. B., Apelberg, B. J., Kaufman, A. R., \& Choiniere, C. J. (2014). Perceptions of the relative harm of cigarettes and e-cigarettes among U.S. youth. American Journal of Preventive Medicine, 47(2Suppl. 1), S53-S60. doi:10.1016/j.amepre.2014.04.016

Amrock, S. M., Zakhar, J., Zhou, S., \& Weitzman, M. (2015). Perception of e-cigarette harm and its correlation with use among U.S. adolescents. Nicotine \& Tobacco Research, 17, 330-336. doi:10.1093/ntr/ntu156

Auer, R., Concha-Lozano, N., Jacot-Sadowski, I., Cornuz, J., \& Berthet, A. (2017). Heat-not-burn tobacco cigarettes: Smoke by any other name. JAMA Internal Medicine, 177, 1050-1052. doi:10.1001/jamainternmed.2017.1419

Barnett, T. E., Soule, E. K., Forrest, J. R., Porter, L., \& Tomar, S. L. (2015). Adolescent electronic cigarette use: Associations with conventional cigarette and hookah smoking. American Journal of Preventive Medicine, 49, 199-206.

Barrington-Trimis, J. L., Berhane, K., Unger, J. B., Cruz, T. B., Huh, J., Leventhal, A. M., . . Gilreath, T. D. (2015). Psychosocial factors associated with adolescent electronic cigarette and cigarette use. Pediatrics, $136,308-317$.

Barrington-Trimis, J. L., Berhane, K., Unger, J. B., Cruz, T. B., Urman, R., Chou, C. P., . . Gilreath, T. D. (2016). The e-cigarette social environment, e-cigarette use, and susceptibility to cigarette smoking. Journal of Adolescent Health, 59, 75-80.

Benowitz, N. L., \& Goniewicz, M. L. (2013). The regulatory challenge of electronic cigarettes. JAMA, 310, 685-686. doi:10.1001/jama.2013.109501

Bhatnagar, A. (2016). E-cigarettes and cardiovascular disease risk: Evaluation of evidence, policy implications, and recommendations. Current Cardiovascular Risk Reports, 10, 24.

Callahan-Lyon, P. (2014). Electronic cigarettes: Human health effects. Tobacco Control, 23(Suppl. 2), ii36ii40. doi:10.1136/tobaccocontrol-2013-051470 
Campaign for Tobacco-Free Kids. (2018). The facts about Philip Morris international: company is cause of the tobacco problem, not the solution. Retrieved from https://www.tobaccofreekids.org/what-we-do/ industry-watch/pmi-foundation/bad-acts

Chang, A. Y., \& Barry, M. (2015). The global health implications of e-cigarettes. JAMA, 314, 663-664.

Demick, B. (2009). A high-tech approach to getting a nicotine fix. Retrieved from http://articles.latimes. com/2009/apr/25/world/fg-china-cigarettes 25

DeVito, E. E., \& Krishnan-Sarin, S. (2018). E-cigarettes: Impact of e-liquid components and device characteristics on nicotine exposure. Current Neuropharmacology, 16, 438-459. doi:10.2174/15701 59x15666171016164430

Dutra, L. M., Grana, R., \& Glantz, S. A. (2017). Philip Morris research on precursors to the modern e-cigarette since 1990. Tobacco Control, 26(e2), e97-e105. doi:10.1136/tobaccocontrol-2016-053406

East, K., Hitchman, S. C., Bakolis, I., Williams, S., Cheeseman, H., Arnott, D., \& McNeill, A. (2018). The association between smoking and electronic cigarette use in a cohort of young people. Journal of Adolescent Health, 62, 539-547. doi:10.1016/j.jadohealth.2017.11.301

Egbe, C. O. (2018). How South Africa is tightening its tobacco rules. The Conversation. Retrieved from https://theconversation.com/how-south-africa-is-tightening-its-tobacco-rules-97382

Elias, J., \& Ling, P. M. (2018). Invisible smoke: Third-party endorsement and the resurrection of heat-notburn tobacco products. Tobacco Control. doi:10.1136/tobaccocontrol-2018-054433

Farrelly, M. C., Duke, J. C., Crankshaw, E. C., Eggers, M. E., Lee, Y. O., Nonnemaker, J. M., . . Porter, L. (2015). A randomized trial of the effect of e-cigarette TV advertisements on intentions to use e-cigarettes. American Journal of Preventive Medicine, 49, 686-693.

Ford, A., MacKintosh, A. M., Bauld, L., Moodie, C., \& Hastings, G. (2016). Adolescents' responses to the promotion and flavouring of e-cigarettes. International Journal of Public Health, 61, 215-224.

Fromme, H., \& Schober, W. (2015). Waterpipes and e-cigarettes: Impact of alternative smoking techniques on indoor air quality and health. Atmospheric Environment, 106, 429-441.

Gaur, S., \& Agnihotri, R. (2018). Health effects of trace metals in electronic cigarette aerosols-a systematic review. Biological Trace Elements Research. doi:10.1007/s12011-018-1423-x

Gilbert, P. (2017). New smoke-free e-cigarette launches in SA. Retrieved from https://www.itweb.co.za/content/XGxwQDM1mDWMIPVo

Global Tobacco Control. (n.d.-a). Country laws regulating e-cigarettes. Retrieved from https://globaltobaccocontrol.org/node/14052

Global Tobacco Control. (n.d.-b). Country laws regulating e-cigarettes: Policy domain. Retrieved from https://globaltobaccocontrol.org/e-cigarette/policy-domains

Göney, G., Çok, İ., Tamer, U., Burgaz, S., \& Şengezer, T. (2016). Urinary cotinine levels of electronic cigarette (e-cigarette) users. Toxicology Mechanisms and Methods, 26, 441-445.

Goniewicz, M. L., Gawron, M., Smith, D. M., Peng, M., Jacob, P., \& Benowitz, N. L. (2017). Exposure to nicotine and selected toxicants in cigarette smokers who switched to electronic cigarettes: A longitudinal within-subjects observational study. Nicotine \& Tobacco Research, 19, 160-167.

Lerner, C. A., Sundar, I. K., Yao, H., Gerloff, J., Ossip, D. J., McIntosh, S., . . Rahman, I. (2015). Vapors produced by electronic cigarettes and e-juices with flavorings induce toxicity, oxidative stress, and inflammatory response in lung epithelial cells and in mouse lung. PLOS ONE, 10, e0116732.

McGhee, A. (2017). Philip Morris ordered to pay Federal Government's legal fees after plain packaging battle. Retrieved from http://www.abc.net.au/news/2017-07-10/philip-morris-ordered-to-pay-federalgovernment-legal-fees/8692792

Morgenstern, M., Nies, A., Goecke, M., \& Hanewinkel, R. (2018). E-cigarettes and the use of conventional cigarettes: A cohort study in 10(th) grade students in Germany. Deutsches Ärzteblatt International, 115, 243-248. doi:10.3238/arztebl.2018.0243

Muposhi, A., \& Dhurup, M. (2016). Is vaping a panacea or peril? Consumers' attitudes towards electronic cigarettes and relationship with quitting intention: Health. African Journal for Physical Activity and Health Sciences (AJPHES), 22, 655-666.

National Department of Health. (2018, May 9). Control of tobacco products and electronic nicotine delivery systems Bill, 2018. Government Gazette. Retrieved from https://www.gov.za/sites/default/files/41617_ gon475re.pdf 
Pepper, J. K., Ribisl, K. M., \& Brewer, N. T. (2016). Adolescents' interest in trying flavoured e-cigarettes. Tobacco Control. doi:10.1136/tobaccocontrol-2016-053174

Perry, C. L. (1999). The tobacco industry and underage youth smoking: Tobacco industry documents from the Minnesota litigation. Archives of Pediatrics \& Adolescent Medicine, 153, 935-941.

Primack, B. A., Soneji, S., Stoolmiller, M., Fine, M. J., \& Sargent, J. D. (2015). Progression to traditional cigarette smoking after electronic cigarette use among US adolescents and young adults. JAMA Pediatrics, $169,1018-1023$.

Proctor, R. N. (2011). Golden holocaust: Origins of the cigarette catastrophe and the case for abolition. Berkeley: University of California Press.

Republic of South Africa. (2008). Tobacco products control act 83 of 1993: Amendment act 63 of 2008. Retrieved from https://www.tobaccocontrollaws.org/files/live/South\%20Africa/South\%20Africa\%20 -\%20Tobacco\%20Products\%20Control\%20Act\%20-\%20national.pdf

Rigotti, N. A., Chang, Y., Tindle, H. A., Kalkhoran, S. M., Levy, D. E., Regan, S., . . Singer, D. E. (2018). Association of e-cigarette use with smoking cessation among smokers who plan to quit after a hospitalization: A prospective study. Annals of Internal Medicine, 168, 613-620. doi:10.7326/m17-2048

Rubinstein, M. L., Delucchi, K., Benowitz, N. L., \& Ramo, D. E. (2018). Adolescent exposure to toxic volatile organic chemicals from e-cigarettes. Pediatric, 141(4). doi:10.1542/peds.2017-3557

Shi, Y., Pierce, J. P., White, M., Vijayaraghavan, M., Compton, W., Conway, K., . . Messer, K. (2016). E-cigarette use and smoking reduction or cessation in the 2010/2011 TUS-CPS longitudinal cohort. BMC Public Health, 16, 1105. doi:10.1186/s12889-016-3770-x

Siqueira, L. M. and AAP Committee on Substance Use and Prevention (2017). Nicotine and tobacco as substances of abuse in children and adolescents. Pediatrics, 139(1). doi:10.1542/peds.2016-3436

Soneji, S., Barrington-Trimis, J. L., Wills, T. A., Leventhal, A. M., Unger, J. B., Gibson, L. A., . . Sargent, J. D. (2017). Association between initial use of e-cigarettes and subsequent cigarette smoking among adolescents and young adults: A systematic review and meta-analysis. JAMA Pediatrics, 171, 788-797. doi:10.1001/jamapediatrics.2017.1488

Soneji, S. S., Sung, H. Y., Primack, B. A., Pierce, J. P., \& Sargent, J. D. (2018). Quantifying population-level health benefits and harms of e-cigarette use in the United States. PLOS ONE, 13, e0193328. doi:10.1371/ journal.pone. 0193328

US Department of Health and Human Services. (1964). Smoking and health: Report of the advisory committee to the Surgeon General of the public health service. Retrieved from https://profiles.nlm.nih.gov/ps/ retrieve/ResourceMetadata/NNBCXB

US Department of Health and Human Services. (2016). E-cigarette use among youth and young adults: A report of the surgeon general. Atlanta, GA: US Department of Health and Human Services, Centers for Disease Control and Prevention, National Center for Chronic Disease Prevention and Health Promotion, Office on Smoking and Health. Retrieved from https://e-cigarettes.surgeongeneral.gov/documents/2016 sgr_full_report_non-508.pdf

Wang, M. P., Li, W. H., Jiang, N., Chu, L. Y., Kwong, A., Lai, V., \& Lam, T. H. (2015). E-Cigarette awareness, perceptions and use among community-recruited smokers in Hong Kong. PLoS ONE, 10, e0141683. doi:10.1371/journal.pone.0141683

Warner, K. E., \& Mendez, D. (2018). E-cigarettes: Comparing the possible risks of increasing smoking initiation with the potential benefits of increasing smoking cessation. Nicotine \& Tobacco Research. Advance online publication. doi:10.1093/ntr/nty062

WHO FCTC. (2016). Electronic nicotine delivery systems and electronic non-nicotine delivery systems. Retrieved from http://www.who.int/fctc/cop/cop7/FCTC_COP7_9_EN.pdf

World Health Organization. (2003). WHO framework convention on tobacco control. Retrieved from http:// apps.who.int/iris/bitstream/handle/10665/42811/9241591013.pdf;jsessionid=FFED84E416EA13428A FC5BDF37AB0272? sequence $=1$

Zhong, J., Cao, S., Gong, W., Fei, F., \& Wang, M. (2016). Electronic cigarettes use and intention to cigarette smoking among never-smoking adolescents and young adults: A meta-analysis. International Journal of Environmental Research and Public Health, 13, 465. 